\title{
Major cereal crops benefit from biological nitrogen fixation when inoculated with the nitrogen-fixing bacterium Pseudomonas...
}

Article in Environmental Microbiology · October 2016

CITATION

1

12 authors, including:

\section{Claudio Valverde}

National University of Quilmes

96 PUBLICATIONS 1,536 CITATIONS

SEE PROFILE

Ray Alan Dixon

John Innes Centre

210 PUBLICATIONS 8,166 CITATIONS

SEE PROFILE

\section{READS}

1,172
Jesús Mercado-Blanco

Spanish National Research Council

87 PUBLICATIONS 2,091 CITATIONS

SEE PROFILE

Nicolas Daniel Ayub

Instituto Nacional de Tecnología Agropecuaria 28 PUBLICATIONS 405 CITATIONS

SEE PROFILE

Some of the authors of this publication are also working on these related projects: 


\section{Major cereal crops benefit from biological nitrogen fixation when inoculated with the nitrogen-fixing bacterium Pseudomonas protegens Pf-5 X940}

\author{
Ana Romina Fox, ${ }^{1,2}$ Gabriela Soto, ${ }^{1,2}$ \\ Claudio Valverde,, ${ }^{1,3}$ Daniela Russo, ${ }^{1,4}$ \\ Antonio Lagares, Jr, ${ }^{1,3}$ Ángeles Zorreguieta, ${ }^{1,4}$ \\ Karina Alleva, ${ }^{1,5}$ Cecilia Pascuan, ${ }^{1,2}$ \\ Romina Frare, ${ }^{1,2}$ Jesús Mercado-Blanco, ${ }^{6}$ \\ Ray Dixon ${ }^{7}$ and Nicolás Daniel Ayub ${ }^{1,2 \star}$ \\ ${ }^{1}$ Consejo Nacional de Investigaciones Científicas y \\ Técnicas (CONICET), Cuidad Autónoma de Buenos \\ Aires, Buenos Aires, Argentina. \\ ${ }^{2}$ Instituto de Genética Ewald A. Favret (CICVyA-INTA), \\ Buenos Aires, Argentina. \\ ${ }^{3}$ LBMIBS, Departamento de Ciencia y Tecnología, \\ Universidad Nacional de Quilmes, Buenos Aires, \\ Argentina. \\ ${ }^{4}$ Fundación Instituto Leloir and IIBBA CONICET, \\ Buenos Aires, Argentina. \\ ${ }^{5}$ Departamento de Fisicomatemática, Facultad de \\ Farmacia y Bioquímica, Universidad de Buenos Aires, \\ Buenos Aires, Argentina. \\ ${ }^{6}$ Department of Crop Protection, Institute for \\ Sustainable Agriculture, Agencia Estatal Consejo \\ Superior de Investigaciones Científicas (CSIC), \\ Córdoba, Spain. \\ ${ }^{7}$ Department of Molecular Microbiology, John Innes \\ Centre, Norwich, NR4 7UH, UK.
}

\section{Summary}

A main goal of biological nitrogen fixation research has been to expand the nitrogen-fixing ability to major cereal crops. In this work, we demonstrate the use of the efficient nitrogen-fixing rhizobacterium Pseudomonas protegens Pf-5 X940 as a chassis to engineer the transfer of nitrogen fixed by BNF to maize and wheat under non-gnotobiotic conditions. Inoculation of maize and wheat with Pf-5 X940 largely improved nitrogen content and biomass accumulation in both vegetative and reproductive tissues, and

${ }^{*}$ For correspondence. E-mail nicoayub@gmail.com; Tel. 54-1144500805-136; Fax 54-11-44500805. this beneficial effect was positively associated with high nitrogen fixation rates in roots. ${ }^{15} \mathrm{~N}$ isotope dilution analysis showed that maize and wheat plants obtained substantial amounts of fixed nitrogen from the atmosphere. Pf-5 X940-GFP-tagged cells were always reisolated from the maize and wheat root surface but never from the inner root tissues. Confocal laser scanning microscopy confirmed root surface colonization of Pf-5 X940-GFP in wheat plants, and microcolonies were mostly visualized at the junctions between epidermal root cells. Genetic analysis using biofilm formation-related Pseudomonas mutants confirmed the relevance of bacterial root adhesion in the increase in nitrogen content, biomass accumulation and nitrogen fixation rates in wheat roots. To our knowledge, this is the first report of robust BNF in major cereal crops.

\section{Introduction}

Nitrogen is essential to all living systems. Although dinitrogen is the most abundant gas in the Earth's atmosphere (78\%), most organisms are not known to use this molecular form. Consequently, these organisms depend on fixed nitrogen for their nutritional requirements. Biological nitrogen fixation (BNF), i.e. the ATP-dependent reduction of dinitrogen to bioavailable ammonia, is widespread among prokaryotes but completely absent in multicellular organisms (Dos Santos et al., 2012). However, BNF can directly benefit eukaryotes, including plants, animals and fungi, through symbiotic and endophytic associations with nitrogen-fixing bacteria and archaea, the best known example being the legume-rhizobium symbiosis (Oldroyd et al., 2011).

Due to the limited bioavailability of nitrogen in the form of ammonium and nitrates, and the dependence of plant growth on these elements, nitrogen fertilizer application has been a crucial input for the high crop yields that drive modern agriculture (Galloway et al., 2008). Unfortunately, a vast amount of non-renewable fossil fuel is required for the production and delivery of nitrogen fertilizers (Erisman et al., 2007). In the last decade, the price of nitrogen 
(a)

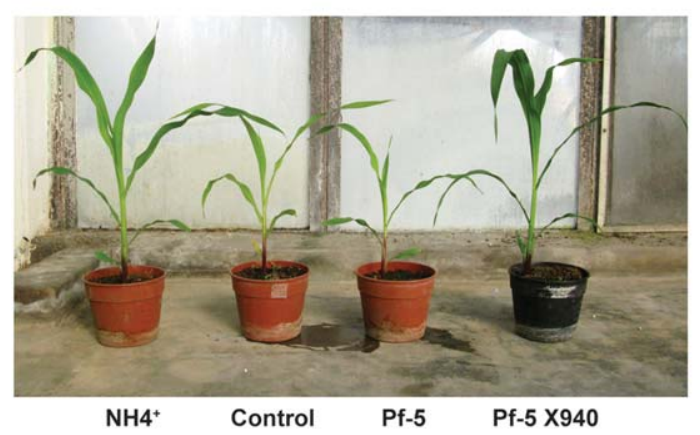

(d)

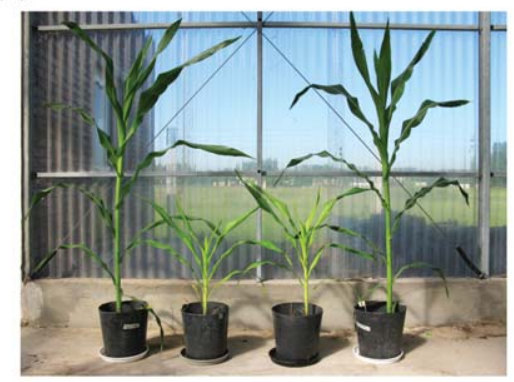

$\mathrm{NH}^{+}{ }^{+}$Control Pf-5 Pf-5 $\mathrm{X} 940$ (b)

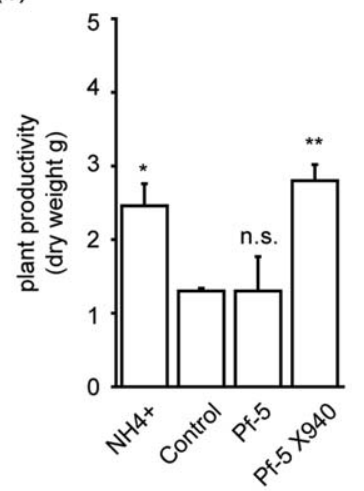

(e)

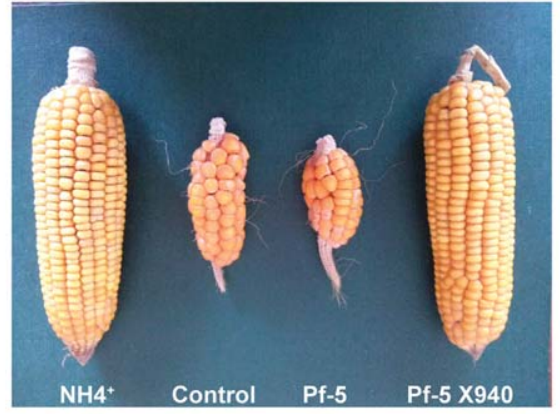

(c)

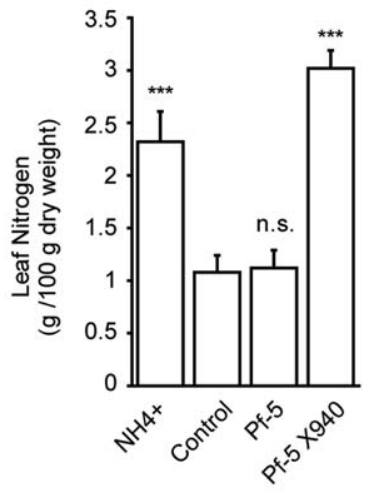

(f)

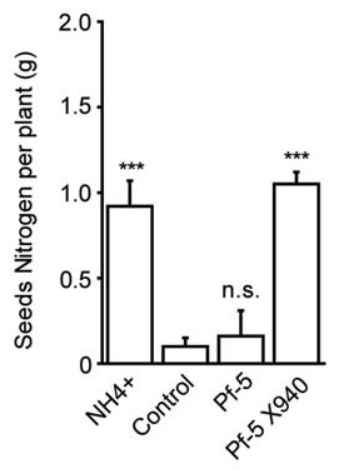

(g)

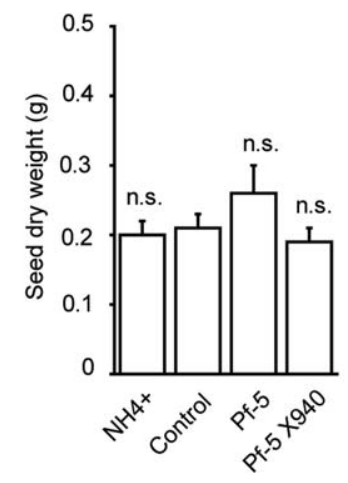

(h)

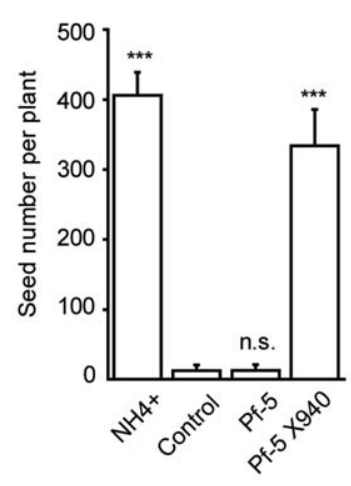

(i)

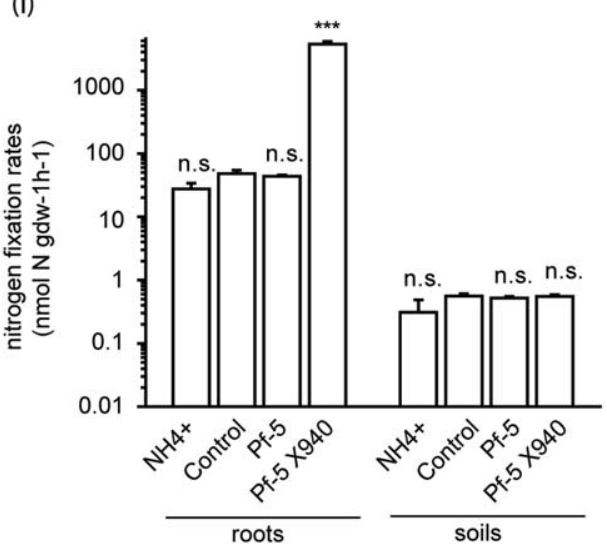

Fig. 1. Effects of the inoculation with Pf-5 X940 on maize productivity and nitrogen content. The biomass and nitrogen content of maize plants was analysed after exposure to four differential treatments: supplementation with ammonium $\left(\mathrm{NH}_{4}^{+}\right)$, no supplementation (Control), inoculation with the non-nitrogen fixing wild-type strain (Pf-5), and inoculation with the isogenic nitrogen-fixing strain (Pf-5 X940).

A. Representative images of two-month-old maize plants in 1-L pots.

B. Dry weight of two-month-old maize plants in 1-L pots.

C. Total nitrogen content in leaves from two-month-old maize plants in 1-L pots.

D. Representative images of maize plants in 10-L pots.

E. Representative images of corns from maize plants in 10-L pots.

F. Total nitrogen content in seeds from maize plants in 10-L pots.

G. Dry weight of seeds from maize plants in 10-L pots.

$H$. Seed production of maize plants in $10-L$ pots.

I. Nitrogen fixation rates within root and soil compartments after 2 months of treatment with the inoculants.

The statistical analysis was carried out with ANOVA followed by Dunnett's contrast test ${ }^{\star \star \star} P<0.0001,{ }^{\star \star} P<0.001^{\star}, P<0.05$, n.s. not significant). All values are means + SEM $(n=24)$. 
(a)

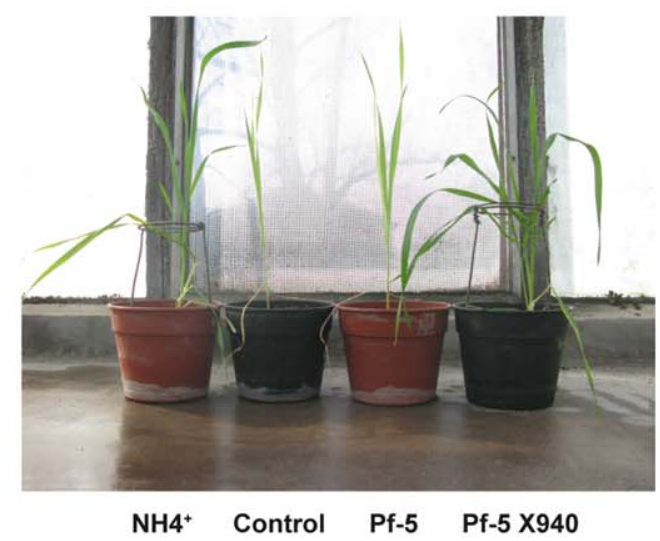

(d)

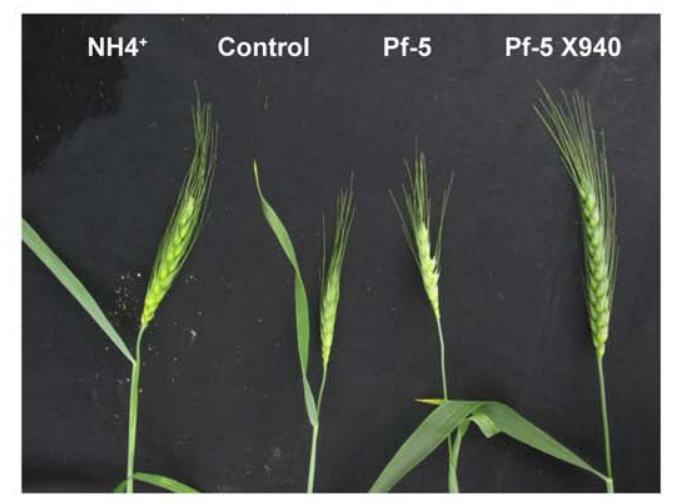

(f)

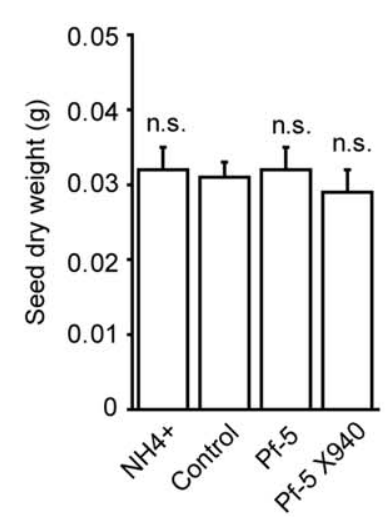

(b)
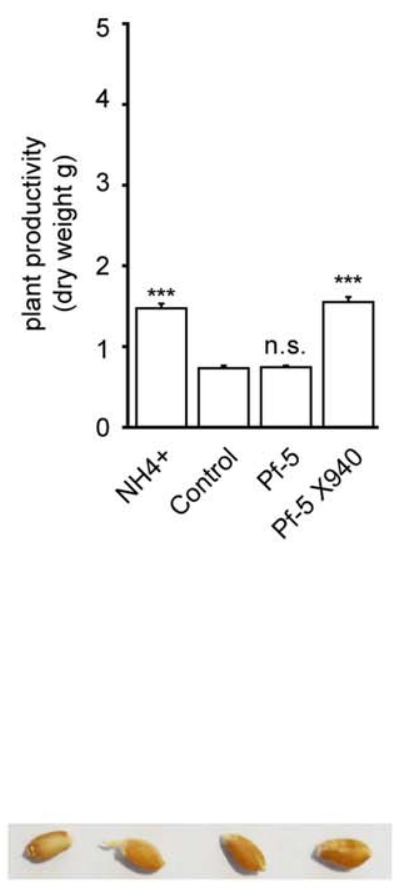

$\mathrm{NH}^{+}$Control Pf-5 Pf-5 X940

(c)

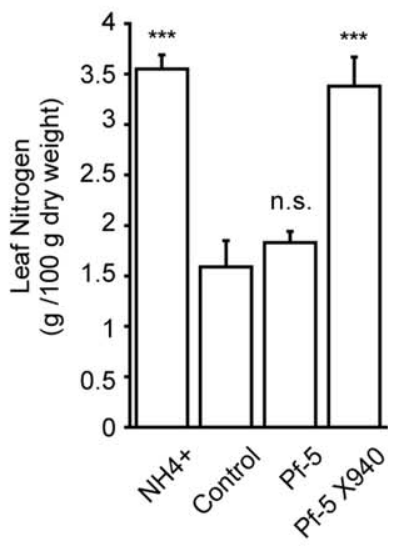

(e)

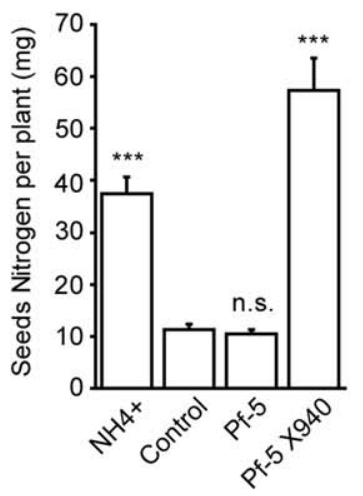

(h)

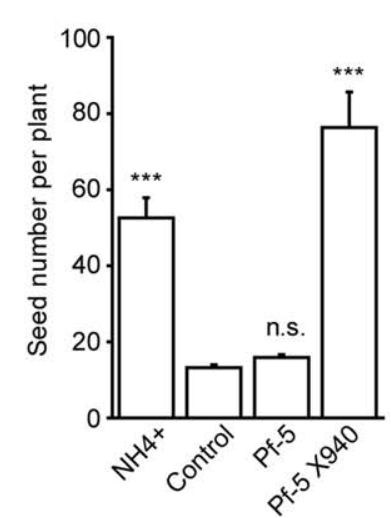

Fig. 2. Effects of the inoculation with Pf-5 X940 on wheat productivity and nitrogen content. The biomass and nitrogen content of wheat plants was analysed after exposure to four differential treatments: supplementation with ammonium ( $\mathrm{NH} 4^{+}$), no supplementation (Control), inoculation with the non-nitrogen fixing wild-type strain (Pf-5), and inoculation with the isogenic nitrogen-fixing strain (Pf-5 X940).

A. Representative images of two-month-old wheat plants.

B. Dry weight of two-month-old wheat plants.

C. Total nitrogen content in leaves from two-month-old wheat plants.

D. Representative images of wheat spikes (left) and seeds (right).

E. Total nitrogen content in seeds from wheat plants.

F. Dry weight of seeds from wheat plants.

G. Seed production of wheat plants.

$\mathrm{H}$. Nitrogen fixation rates within root and soil compartments after 2 months of treatment with the inoculants.

The statistical analysis was carried out with ANOVA followed by Dunnett's contrast test $\left({ }^{\star \star \star} P<0.0001\right.$, n.s. not significant). All values are means + SEM $(n=24)$. 


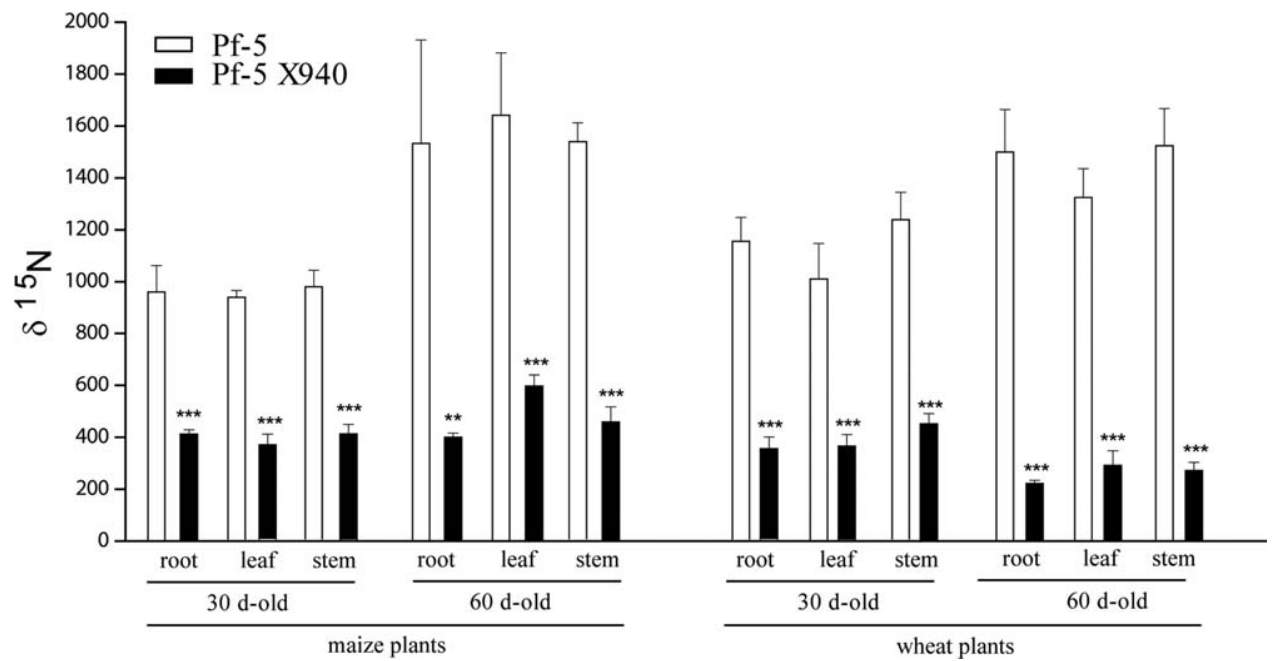

Fig. 3. Quantification of biological nitrogen fixation in strain Pf-5X940-inoculated maize and wheat plants. For the evaluation of BNF in maize and wheat plants inoculated with Pf-5 or Pf$5 \times 940$ using the isotope dilution assay, the ${ }^{15} \mathrm{~N}$ atmospheric excess was analysed in different tissues after 1 or 2 months of treatment with the inoculants. All values are means + SEM $(n=20)$. Statistically significant differences between $\delta^{15} \mathrm{~N}$ levels are indicated by asterisks (Student's $t$-test, ${ }^{* *} P<0.01$, $\left.{ }^{\star * \star} P<0.0001\right)$. fertilizers has increased more than $300 \%$, mainly due to rising fossil fuel costs, partially related to the dwindling petroleum reserves (USDA, 2014). Additionally, nitrogen fertilizer application results in high emission of greenhouse gases, which constitute a key factor in climate change. Chemical nitrogen delivery is a largely inefficient process because around half of the nitrogen fertilizer applied is lost to leaching, resulting in significant health and environmental problems (Olivares et al., 2013). Therefore, replacing chemical nitrogen fixation, both totally or partially, by BNF can attenuate our dependence on fossil fuels thereby generating a new perspective of agricultural sustainability (Farrar et al., 2014).

Since the 1970s, when the first transfer of the nitrogenase complex was carried out, specifically the horizontal transfer of the nif cluster from the facultative anaerobe Klebsiella pneumoniae to Escherichia coli (Dixon and Postgate, 1971), scientists have speculated about the possibility of engineering cereal crops that could be selfsupported by BNF (Venkateshwaran, 2015). There is a renewed interest in engineering these types of major crops for BNF and three general approaches have been recently proposed: (i) expressing heterologous nitrogenase in plant cells, (ii) engineering the symbiotic nodule into nonnodulating plants, and (iii) using plant-associative diazotrophs to fix nitrogen for the benefit of their non-legume host plants (Santi et al., 2013; Oldroyd and Dixon, 2014; Geddes et al., 2015). However, despite the remarkable advances in synthetic biology (Temme et al., 2012; Wang et al., 2013a; Wang et al., 2013b; Yang et al., 2014), this progress is not automatically extrapolated to any bacteria, mainly because most plant-colonizing microbes and plants themselves are aerobic organisms and nitrogenase is oxygen-sensitive (Stueken et al., 2015). In addition, accessory factors for the protection of nitrogenase against oxygen are not yet understood (Geddes et al., 2015). Engi- neering bacterial competitiveness, persistence in the rhizosphere and ammonium release are also key steps for an efficient translation of the fixed nitrogen to plants (Geddes et al., 2015).

Recently, we have transferred a genomic island (X940) with demonstrated nitrogenase activity from the polyhydroxybutyrate $(\mathrm{PHB})$ - producing strain Pseudomonas stutzeri A1501 to the aerobic root-associated beneficial bacterium Pseudomonas protegens Pf- 5 . The nitrogenfixing strain $P$. protegens $\mathrm{Pf}-5 \mathrm{X} 940$ showed unrepressed expression of both nitrogenase structural and biosynthetic genes in association with the presence of high levels of nitrogenase activity (Setten et al., 2013). In addition, we have demonstrated that heterologous PHB production can regulate heterologous nitrogenase activity in $P$. protegens Pf-5 X940 (Pascuan et al., 2015). Interestingly, we have also shown that inoculation of different flowering plant species with Pf-5 X940 increases plant growth under sterile hydroponic growth-chamber conditions and that this beneficial effect could be attributed to the excretion of a high amount of ammonium to the medium (Setten et al., 2013). In the present study, we demonstrate the use of the plantcolonizing bacterium Pf-5 X940 to support the nitrogen requirements of maize and wheat under non-gnotobiotic soil greenhouse conditions.

\section{Results and discussion}

\section{Effects of inoculation with Pf-5 X940 on maize and wheat productivity and nitrogen content}

To analyse the impact of the ammonium-excreting strain Pf-5 X940 on major cereal crops, we assessed the effect of the inoculation of this bacterium on the productivity and nitrogen content of maize and wheat plants by using an experimental system with non-gnotobiotic agronomic soil under greenhouse conditions. Plants were exposed to four 
(a)

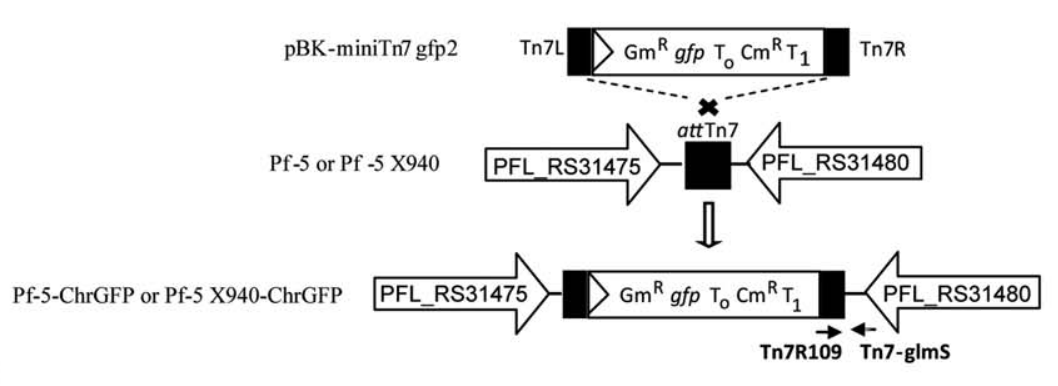

(b)

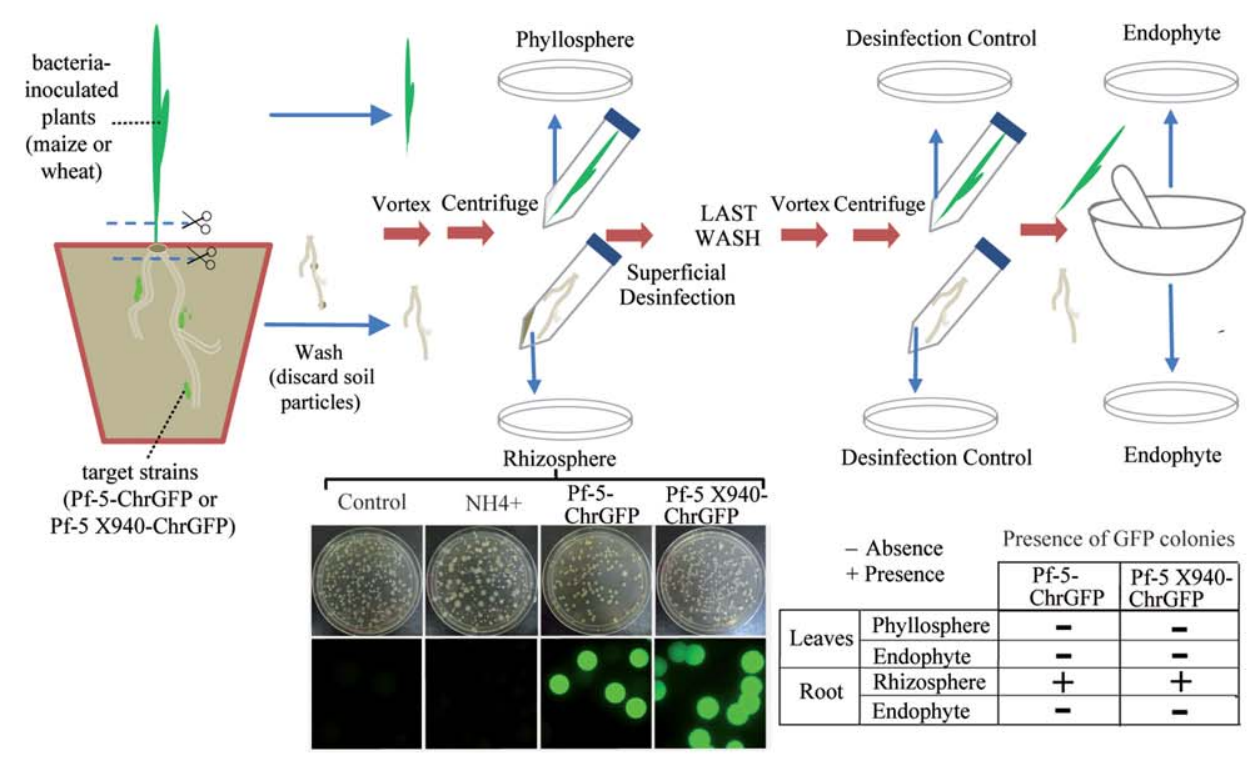

(c)
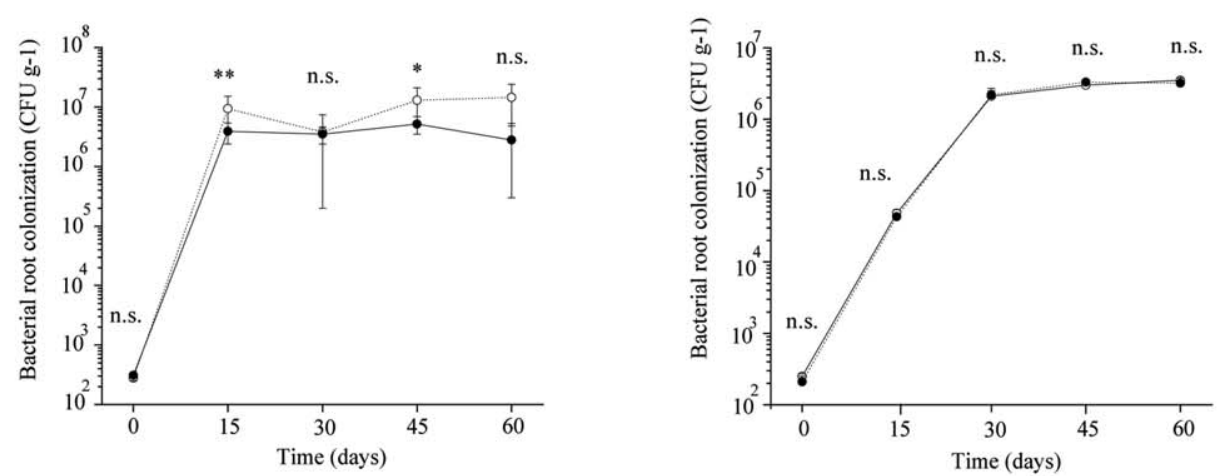

(d)

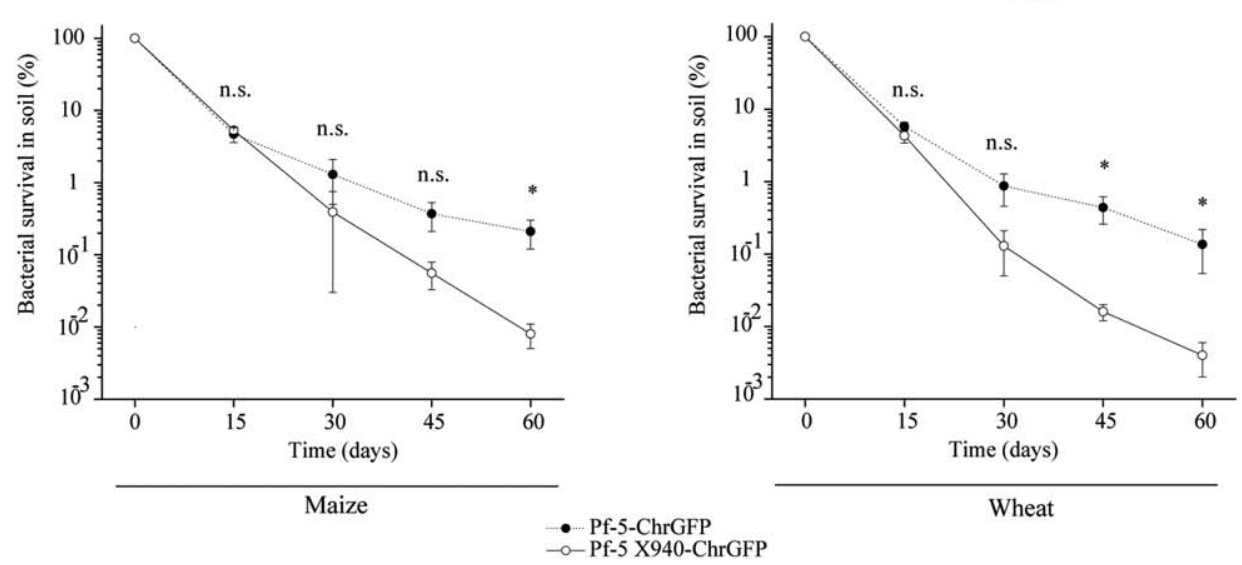

(๔ 2016 Society for Applied Microbiology and John Wiley \& Sons Ltd, Environmental Microbiology, 00, 00-00 
Fig. 4. Tagging of bacterial strains with chromosomal GFP markers and localization patterns of strain Pf-5 X940 in maize and wheat plants. A. GFP genomic tagging of Pseudomonas protegens strains (Pf-5-ChrGFP and Pf5 X940-ChrGFP) by a chromosomal insertion at a predictable neutral att site downstream of the glmS gene (PFL_RS31480) was obtained by using the gfp delivery vector pBK-miniTn7-gfp2. $\mathrm{Gm}^{\mathrm{R}}$, gentamicin resistance; $\mathrm{Cm}^{\mathrm{R}}$, chloramphenicol resistance; mob+, mobilizable plasmid; To and T1, transcriptional terminators. Tn7R109 and Tn7-glmS primers were used to confirm the correct GFP cassette insertion downstream of the glmS gene.

B. Scheme showing the procedure designed to re-isolate strains Pf-5-ChrGFP and Pf5 X940-ChrGFP from different plant localizations (phyllosphere, rhizosphere, and endosphere) after 2 months of bacterial inoculation. A detection limit of $1 \times 10^{-1}$ CFU of GFP-tagged-derived Pseudomonas strains/g of tissue was used. Each experiment was performed at least eight times and typical results are presented. C. Colonization of Pf-5-ChrGFP and its nitrogen-fixing isogenic strain Pf5 X940-ChrGFP in root samples. The amount of bacteria in soil samples was determined in maize (left panel) and wheat (right panel) inoculation experiments under non-gnotobiotic soil greenhouse conditions. The statistical analysis was carried out with Student's $t$-test $\left({ }^{* *} P<0.01,{ }^{*} P<0.05\right.$, n.s. not significant). All values are means + SEM $(n=16)$.

D. Survival of Pf-5-ChrGFP and its nitrogen-fixing isogenic strain Pf5 X940-ChrGFP in soil samples. The amount of bacteria in soil samples was determined in maize (left panel) and wheat wheat (right panel) inoculation experiments under non-gnotobiotic soil greenhouse conditions. One hundred percent survival was considered to be the number of bacteria at time zero $\left(2 \times 10^{6} \mathrm{CFU} \mathrm{g}^{-1}\right.$ soil). The statistical analysis was carried out with Student's $t$-test $\left({ }^{*} P<0.05\right.$, n.s. not significant). All values are means + SEM $(n=16)$.

differential treatments: supplementation with fixed nitrogen $\left(\mathrm{NH}^{+}\right)$, no supplementation (control), and inoculation either with the non-fixing wild-type strain Pf-5 or its isogenic nitrogen-fixing strain Pf-5 X940. Similarly to that observed in field conditions in the absence of added nitrogen fertilization (Witcombe et al., 2008), the untreated plants and Pf-5-treated plants had a significantly lower biomass and nitrogen content than nitrogensupplemented plants in both vegetative and reproductive tissues (Figs $1 \mathrm{~A}-\mathrm{H}$ and $2 \mathrm{~A}-\mathrm{G}$ ). More importantly, this phenotype was completely reversed by inoculation with Pf-5 X940 (Figs 1A-H and 2A-G). Maize plants inoculated with $\mathrm{Pf}-5 \mathrm{X} 940$ had increases of $115 \%$ in biomass accumulation (Fig. 1A-D), of $170 \%$ in nitrogen content of leaves (Fig. 1C), of $556 \%$ in nitrogen content in seeds (Fig. 1F) and of $2489 \%$ in terms of seed yield (Fig. 1E, $G$ and $H$ ), with respect to plants inoculated with the parental isogenic strain Pf-5. Similarly, wheat plants inoculated with Pf-5 X940 showed increases of $112 \%$ in biomass accumulation (Fig. $2 \mathrm{~A}$ and $\mathrm{B}$ ), of $85 \%$ in nitrogen content of leaves (Fig. 2c), of $379 \%$ in seed yield (Fig. 2D, F and G), and of $473 \%$ in seed nitrogen (Fig. $2 E)$, compared with plants inoculated with strain Pf-5. Similar to Pf-5 X940-treated Arabidopsis plants growing under sterile hydroponic growth-chamber conditions (Setten et al., 2013), the phenotypic reversion of nitrogen deficiency in maize and wheat plants by Pf-5 X940 was positively associated with an increase in the inorganic nitrogen levels in non-gnotobiotic soil (Fig. S1). In addition, soil microbial activity was also increased in Pf-5 X940-treated maize and wheat plants (Fig. S2), which could be attributed to increasing amounts of root exudates (Welsh, 2000). Finally, the nitrogen fixation rates associated with isolated roots and soil without roots from the rhizosphere of the Pf-5 X940-treated maize and wheat plants were significantly increased only in isolated roots when exposed to Pf-5 X940 (Figs 1 I and $2 \mathrm{H}$ ), showing that nitrogen fixation is active in this organ.

\section{Quantification of BNF in Pf-5 X940-treated maize and wheat plants}

Substantial levels of BNF have been well documented in non-legume plant species such as elephant grasses (de Morais et al., 2011), oil palms (Zakry et al., 2012) and poplar trees (Knoth et al., 2014) inoculated with either nitrogen-fixing single-strain or multi-strain consortia. In this study, we performed stable-isotope dilution analysis of inoculated plants, grown in greenhouse conditions with ${ }^{15} \mathrm{~N}$ supplemented soil, to measure the level of nitrogen fixation associated with Pf-5 X940-treated maize and wheat plants in comparison with plants inoculated with the non-fixing wild-type strain Pf-5 (Fig. 3). One month after inoculation, the $\delta^{15} \mathrm{~N}$ value was significantly lower in root, leaf and stem tissues of Pf-5 X940-treated maize and wheat plants than in those of Pf-5-treated plants (Fig. 3), suggesting that nitrogen fixation is active since the early stages of plant growth. Two months after inoculation, and relative to control Pf-5-treated maize and wheat plants, the nitrogen derived from gaseous nitrogen (\%Ndfa) in different Pf-5 X940-treated maize and wheat plant organs was $74 \%$ and $85 \%$ for roots, $63 \%$ and $78 \%$ for leaves and $70 \%$ and $82 \%$ for stems respectively (Fig. 3). These results provide further evidence that maize and wheat plants are incorporating the nitrogen provided by BNF under nongnotobiotic soil greenhouse conditions.

\section{Localization pattern of Pf-5 X940 in maize and wheat plants}

Although $P$. protegens Pf-5 was isolated from the cotton rhizosphere and is traditionally described as a rootcolonizing strain (Loper et al., 2007), no empirical evidence on the capacity of Pf-5 to colonize plant tissues has yet been reported. Additionally, the ability of Pf-5 X940 to fix nitrogen could change its plant-localization pattern with respect to the parent strain $\mathrm{Pf}-5$. In this context, standard 
(a)
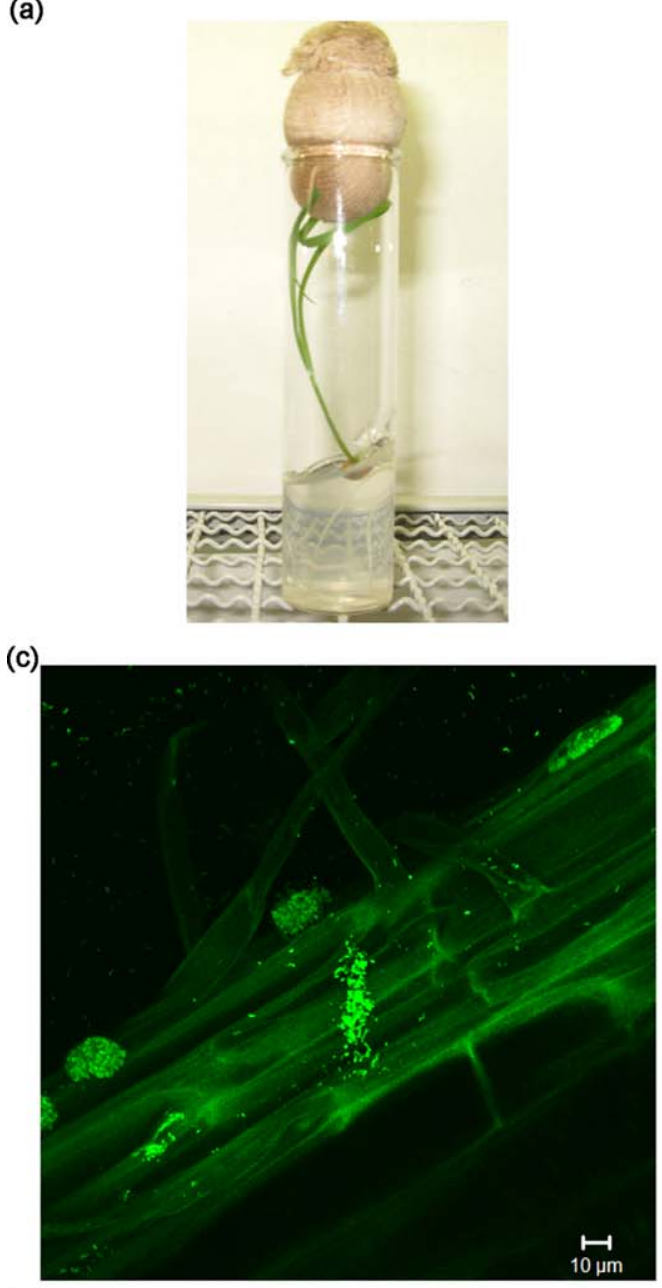

(e)

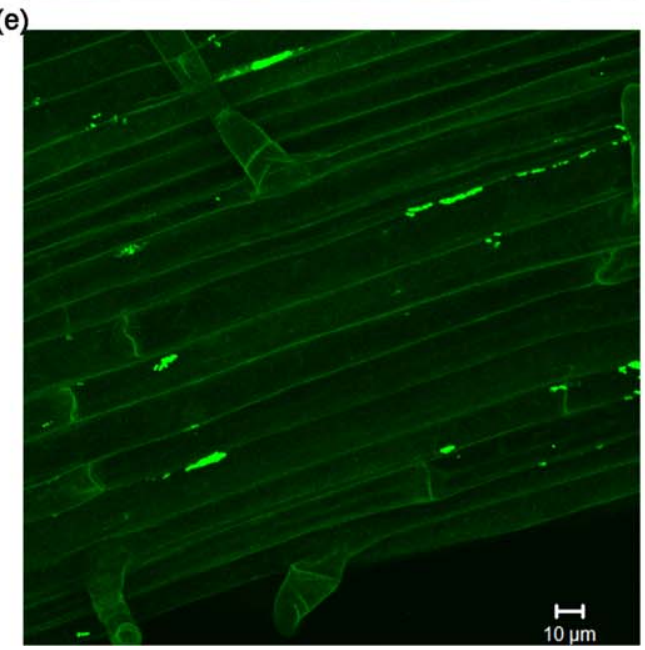

selective plating studies in minimal medium containing both chloramphenicol and octanoate as selective agents, coupled with fluorescence detection of Pseudomonas Pf-5 strains (Pf-5-ChrGFP and Pf5 X940-ChrGFP) carrying a

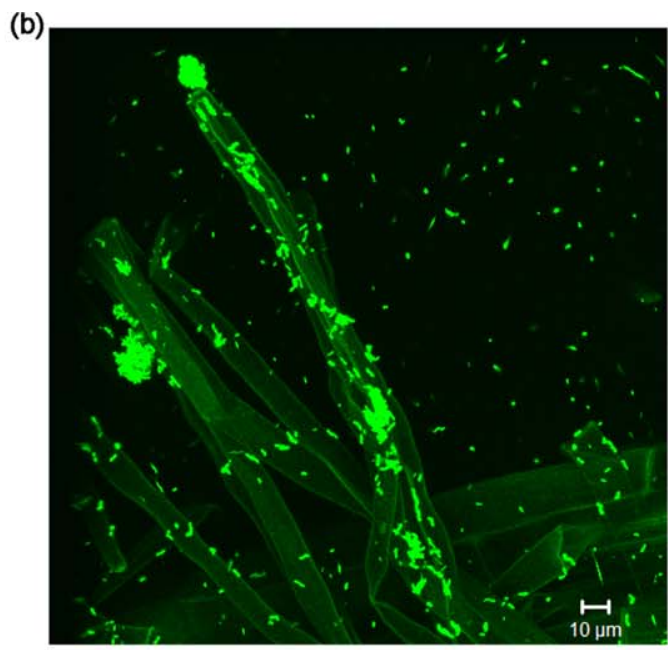

(d)

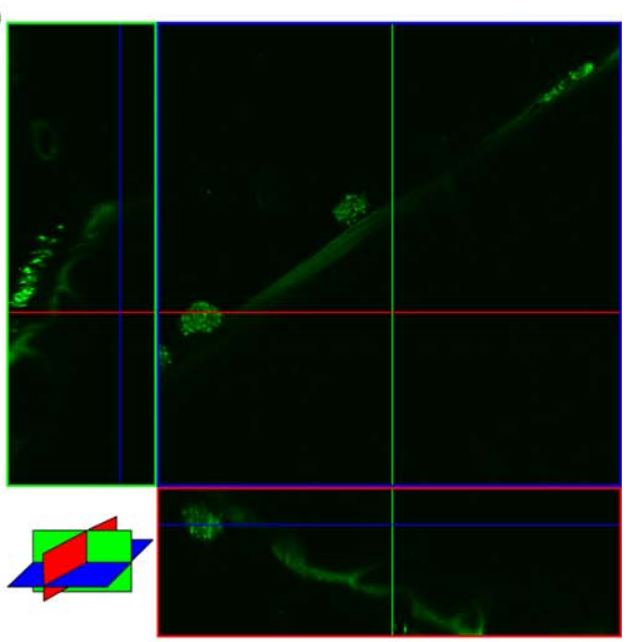

(f)

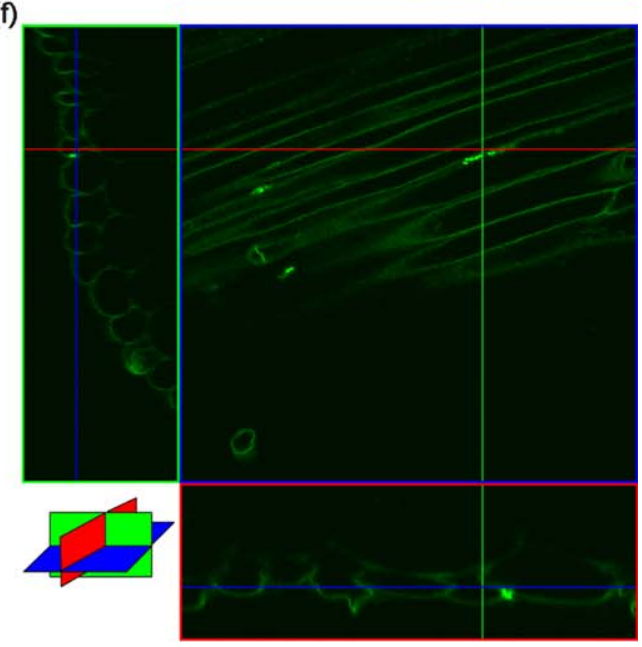

stable and non-transmissible chromosomal single copy of the green fluorescent protein (GFP) (Fig. 4A), were carried out. The localization patterns of Pf-5-ChrGFP and Pf5 X940-ChrGFP in maize and wheat plants grown in non-

(C) 2016 Society for Applied Microbiology and John Wiley \& Sons Ltd, Environmental Microbiology, 00, 00-00 
Fig. 5. Visualization under confocal laser scanning microscopy for fluorescent-tagged bacterium Pf5 X940-pMP4655GFP colonization on the surface of wheat roots.

Wheat plants were removed from the medium 7 days after bacterization with Pf5 X940-pMP4655GFP and root samples were visualized under confocal laser scanning microscopy (CLSM). The colonization pattern of GFP-tagged bacteria was similar during the following 21 days (data not shown). The size bar represents $10 \mu \mathrm{m}$ in all panels.

A. Representative image of axenic wheat plants used for the analysis of bacterial colonization.

B. CLSM image showing Pf5 X940-pMP4655GFP microcolonies on root hairs.

C. CLSM image showing Pf5 X940-pMP4655GFP microcolonies on the surface of a lateral root.

D. Orthogonal planes of image c, showing Pf5 X940-pMP4655GFP microcolonies on the root surface.

E. CLSM image showing dispersed and large microcolonies of Pf5 X940-pMP4655GFP in a lateral root.

F. Orthogonal planes of image e, showing a representative microcolony of Pf5 X940-pMP4655GFP at the epidermal junction cells.

gnotobiotic soil under greenhouse conditions were examined in the phyllosphere, rhizosphere and endosphere (Fig. 4B). Two months after inoculation, Pf-5- and Pf5 X940-tagged cells were found colonizing the rhizoplane of maize and wheat plants but never as endophytes or epiphytes of the phyllosphere or within root tissues (Fig. 4B). The inability of Pf-5-ChrGFP and Pf5 X940-ChrGFP to internally colonize the roots could also impair the colonization of the vascular tissue and further prevent bacteria spread towards the phyllosphere. The long-term stable population size of Pf5 X940-ChrGFP on maize and wheat root surfaces along our experimental timeframe (i.e., 2 months) reached an average of $2.1 \times 10^{6} \mathrm{CFU} \mathrm{g}^{-1}$ and $1.1 \times 10^{7} \mathrm{CFU} \mathrm{g}^{-1}$ of root, respectively, which was not significantly different from that of the control Pf-5-ChrGFP strain (Fig. 4C). In contrast, survival of both Pf-5-ChrGFP and Pf5 X940-ChrGFP decreased rapidly in the soil following inoculation, and population sizes of Pf5 X940-ChrGFP were lower than those of Pf-5-ChrGFP, 60 days after inoculation of maize and wheat (Fig. 4D). Thus, our results may imply that the genetic modification for nitrogen fixation decreases bacterial survival in the rhizosphere in the long term, probably due to the expected fitness cost derived from the acquisition of nitrogen fixation genes (Pascuan et al., 2015), but does not seem to impact upon the ability of the nitrogen-fixing bacteria to colonize the root surface.

\section{Colonization pattern of Pf-5 X940 on the wheat root surface}

By using confocal laser scanning microscopy (CLSM), we monitored the colonization pattern of Pf-5-pMP4655GFP and Pf-5 X940-pMP4655GFP expressing an enhanced GFP encoded by a multiple-copy vector on wheat roots under axenic conditions (Fig. 5A). After 7 days, Pf-5 X940pMP4655GFP cells were localized on both root hairs and lateral roots, forming dispersed and large microcolonies (Fig. 5B-D). Fluorescent-tagged bacteria were always visualized on the root surface but never within root tissues (Fig. 5C-D). The root surface colonized with Pf-5 X940pMP4655GFP clearly displayed the most abundant numbers of microcolonies at the junctions between epidermal plant root cells (Fig. $5 \mathrm{E}-\mathrm{F}$ ), where high concentrations of root exudates are thought to leak from the root (Chin-AWoeng et al., 1997; Peters and Szilagyi, 2006). In addition, CLSM imagery also showed that the colonization pattern of Pf-5-pMP4655GFP cells was similar to that displayed by its derivative strain Pf-5 X940-pMP4655GFP (Fig. S3). The efficient root colonization by Pf- 5 X940, and the abundance of this strain at the junctions between epidermal root cells could explain the nutrient availability to support the high energy demands of nitrogen fixation.

\section{Effects of Pf-5 X940-root adhesion deficiency on wheat productivity and nitrogen content}

Adhesion is a universal root colonization fitness factor for plant beneficial bacteria, including Pseudomonas (Barahona et al., 2010). In Pseudomonas fluorescens strains, large adhesion protein (lapA) is a critical component for biofilm formation, and is specifically required for the initial step of bacterial adhesion (Hinsa et al., 2003; Newell et al., 2009; Duque et al., 2013). Here, we analysed the relevance of bacterial adhesion on the beneficial effects promoted by Pf- 5 X940 in wheat plants using lapA mutant strains (Fig. 6). As expected for biofilm formation-related mutants, lapA mutant strains (Pf-5 lapA::KmR and Pf-5 X940 lapA::KmR) were unable to colonize wheat roots, whereas wild-type lapA strains (Pf-5 and Pf-5 X940) and lapA mutant strains complemented with a wild-type copy of the lapA gene (Pf-5 lapA::KmR+lapA and Pf-5 X940 lapA::KmR+lapA) showed efficient wheat root colonization (Fig. 6A). In addition, lapA mutation seems not to have affected bacterial survival in the soil compartment, which is consistent with a mutation in a structural gene that has no pleiotropic effects (Fig. 6B). In contrast to that observed in Pf-5 X940-treated plants, inoculation of wheat with Pf-5 X940 lapA::KmR did not improve nitrogen content (Fig. $6 C$ ), biomass accumulation (Fig. 6D) or nitrogen fixation rates in roots (Fig. $6 \mathrm{E}$ ), suggesting that root adhesion is a critical factor for the wheat benefit from BNF when inoculated with nitrogen-fixing Pseudomonas. Complementation of the lapA mutation restored the beneficial effects in wheat plants produced by Pf- 5 X940 (Fig. 6C-E), confirming the importance of the close plant-microbe physical interaction for effective BNF. 
(a)

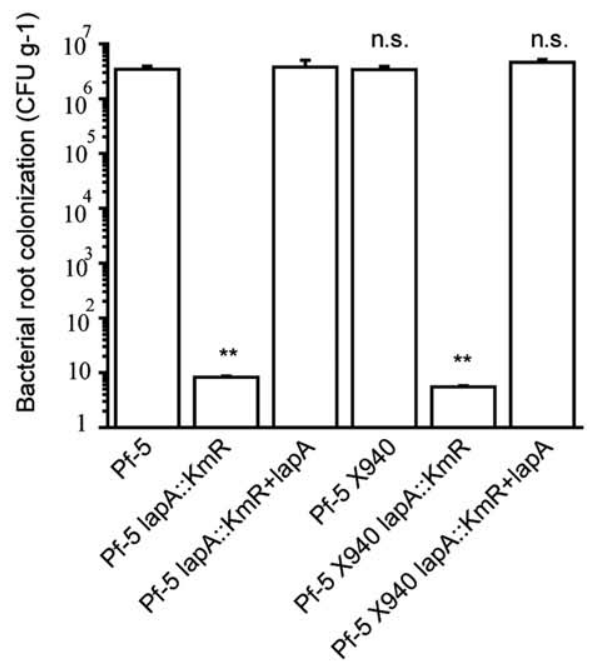

(c)

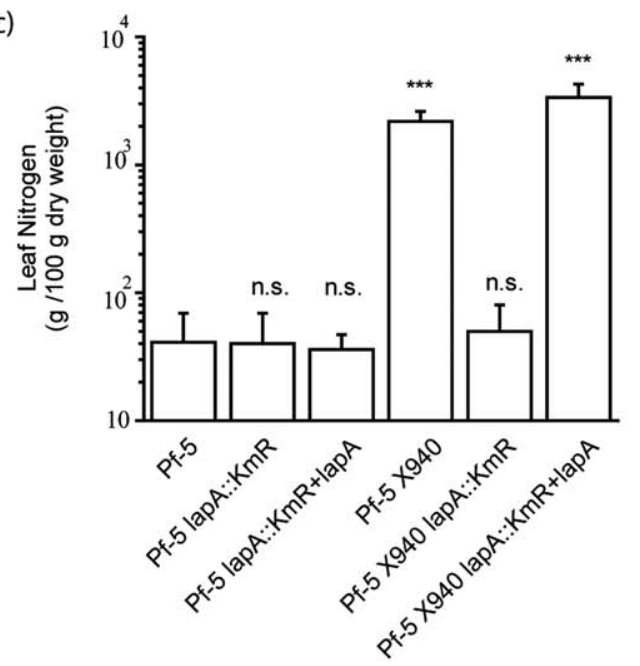

(e)

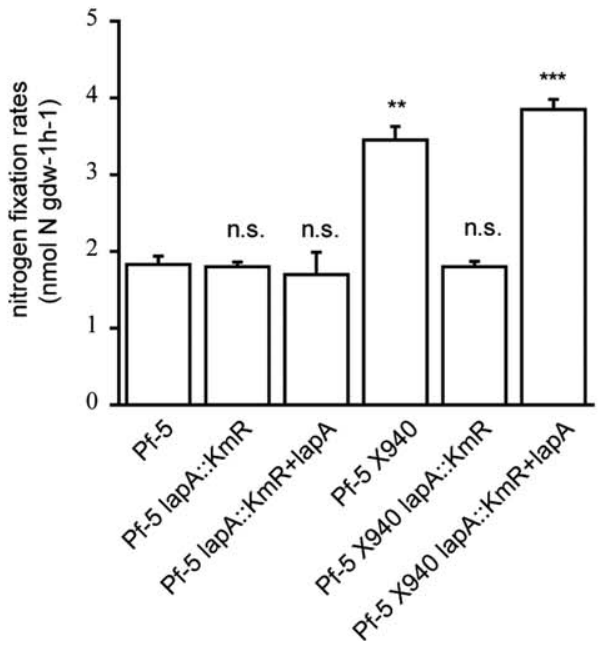

(b)

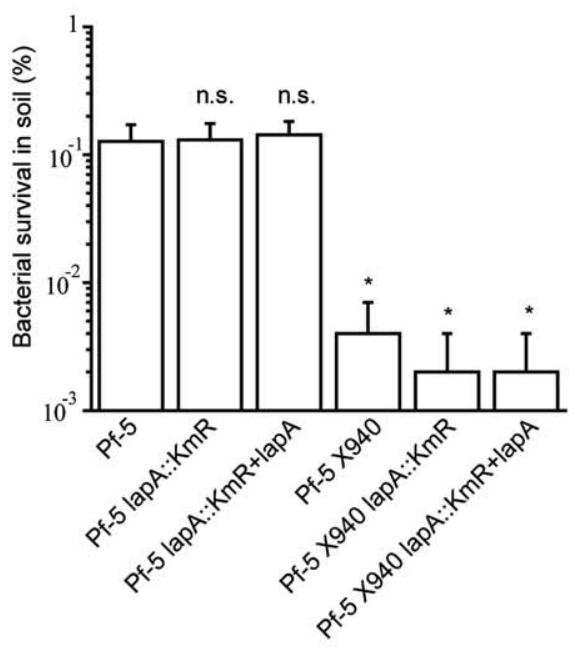

(d)

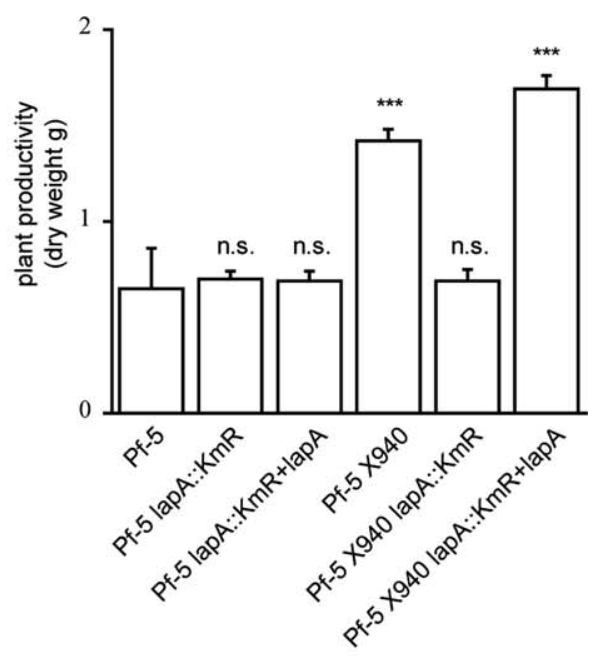

Fig. 6. Effects of Pf-5 X940-root adhesion deficiency on wheat productivity and nitrogen content. Bacterial root colonization, survival of bacteria in soil compartment, plant productivity, leaf nitrogen content and nitrogen fixation rates in roots in 2-month-old wheat plants treated with different bacterial inoculants under non-gnotobiotic soil greenhouse conditions were analysed. The statistical analysis was carried out with ANOVA followed by Dunnett's contrast test $\left({ }^{\star \star \star} P<0.0001,{ }^{\star \star} P<0.001,{ }^{\star} P<0.05\right.$, n.s. not significant). All values are means + SEM $(n=20)$. 


\section{Conclusions}

Previous studies have reported the potential for ammoniaexcreting diazotrophic bacteria to supply fixed nitrogen to non-legume plants, including model plant species or minor crops. Our results show that the ammonia-excreting $P$. protegens Pf-5 X940 strain substantially improves the growth and the nitrogen content of maize and wheat under nongnotobiotic soil greenhouse conditions. This outcome is a consequence of BNF and root colonization by the bacterium is necessary to produce this beneficial effect. Therefore, under tested experimental conditions and for varieties here used, inoculation of major cereal crops with strain Pf-5 X940 can fully replace nitrogen fertilization. The competition with the indigenous microbial communities and the adaptation to different soil oxygen levels could potentially be critical factors affecting BNF in major cereal crops inoculated with strain Pf-5 X940 under field conditions. Related to this, it may be interesting to evaluate whether cereal-endophytic, nitrogen-fixing bacteria, such as P. fluorescens PICF7 (Mercado-Blanco et al., 2016) harboring the X940 cosmid, are capable to overcome such potential constraints, thereby expanding the use of nitrogen-fixing inoculants to diverse climates and soils. To our knowledge, this is the first report of robust BNF in major cereal crops.

\section{Experimental procedures}

\section{Bacterial strains and plant species}

The strains used in this study were the wild type strain Pseudomonas protegens Pf-5 (Howell and Stipanovic, 1979) and its derived strains Pf-5 X940 (Setten et al., 2013), Pf-5 lapA::KmR and Pf-5 lapA::Km+lapA (Ayub et al., 2015). The commercial cereal crops (wheat and maize) used were Triticum aestivum (Bobwhite 26) and Zea mays (Pannar BIOGENE BG6607YR).

\section{Pseudomonas strains containing the GFP marker within} a high-copy-number vector

Pf-5 and Pf5 X940 competent cells were transformed with the multiple-copy vector pMP4655 to constitutively express the enhanced green fluorescent protein (Bloemberg et al., 2000). Briefly, Pseudomonas competent cells were prepared as follows: $500 \mathrm{ml}$ of LB medium was inoculated with $5 \mathrm{ml}$ of an overnight culture and cells were grown under agitation $(250 \mathrm{rpm})$ at $28^{\circ} \mathrm{C}$ until a $0.5 \mathrm{OD}_{600}$. Cultures were chilled on ice for $20 \mathrm{~min}$ and centrifuged at $4000 \times \mathrm{g}$ and $4^{\circ} \mathrm{C}$ for $15 \mathrm{~min}$. Pellets were resuspended in $500 \mathrm{ml}$ of glycerol $10 \% \mathrm{v} \mathrm{v}^{-1}$ previously chilled on ice and centrifuged at $4000 \times g$ and $4^{\circ} \mathrm{C}$ for $15 \mathrm{~min}$. This step was repeated three times, resuspending cells in each step in a smaller volume of $10 \% \mathrm{v} \mathrm{v}^{-1}$ chilled glycerol: 250,20 and $1 \mathrm{ml}$. A volume of $40 \mu \mathrm{l}$ of competent cells was electroporated with the pMP4655 vector (Prieto and Mercado-Blanco, 2008). Transformants were selected by plating on LB agar containing $75 \mu \mathrm{g} \mathrm{ml}^{-1}$ of kanamycin. After incubation at $28^{\circ} \mathrm{C}$ for 24 to $48 \mathrm{~h}$, the colonies that arose were screened for GFP fluorescence under the microscope and magnifying glass. The resulting GFP-tagged strains were named Pf-5-pMP4655GFP and Pf5 X940-pMP4655GFP.

\section{GFP chromosomal tagging of Pseudomonas strains}

A single copy of the gene encoding GFP was introduced at a neutral chromosomal site into strains Pf- 5 and Pf- 5 X940, by using a mini-Tn7 delivery system (Koch et al., 2001). Briefly,

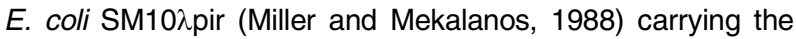
Tn7 transposition helper vector pUX-BF13 (Bao et al., 1991), E. coli DH5 $\alpha$ carrying the gfp delivery vector pBK-miniTn7gfp2 (Koch et al., 2001), E. coli MT616 carrying the mobilizing plasmid pRK600 (Finan et al., 1986), and the target strains Pf5 and Pf- 5 X940 were combined in a tetraparental mating on nutrient agar and incubated overnight at $37^{\circ} \mathrm{C}$. This conjugation mixture was then resuspended in saline solution $(0.9 \%$ $w v^{-1} \mathrm{NaCl}$ ) and spread onto $0.5 \mathrm{NE2}$ medium agar plates (Ayub et al., 2006), where E. coli cannot grow, containing $10 \mu \mathrm{g} \mathrm{ml}^{-1}$ gentamicin (for Pf-5) or $10 \mu \mathrm{g} \mathrm{ml}^{-1}$ gentamicin and $25 \mu \mathrm{g} \mathrm{ml}^{-1}$ kanamycin (for Pf-5 X940). After incubation at $28^{\circ} \mathrm{C}$ for $72-96 \mathrm{~h}$, the colonies that arose were screened for GFP fluorescence under the microscope. Fluorescent and gentamicin-resistant colonies were subjected to colony PCR targeting the Pseudomonas-specific gap-1 gene, and the correct genomic gfp integration at the attTn7 site was confirmed in the colonies positive by PCR with the specific oligonucleotides Tn7R109 and Tn7-glmS (Lambertsen et al., 2004). GFPtagged-derived strains were called Pf-5-ChrGFP and Pf5 X940-ChrGFP.

\section{Plant productivity and nitrogen determinations}

Wheat and maize seeds were sown in 1-I or 10-I pots containing a mixture of soil: vermiculite (1:1), with an average nitrogen content of $21 \mathrm{mg} \mathrm{kg}^{-1}$ (inorganic + organic nitrogen). The soil was collected from the Pampean Region, Buenos Aires, Argentina. This soil, under good agricultural practices, contains diverse indigenous microorganisms (Figuerola et al., 2012). For the inoculation assays, bacteria were prepared as follows: Pf-5 and Pf-5 X940 were grown overnight in LB medium at $28^{\circ} \mathrm{C}$ with shaking $(250 \mathrm{rpm})$, and then centrifuged and resuspended in an equal volume of saline solution $(0.9 \%$ $\mathrm{w} \mathrm{v}^{-1} \mathrm{NaCl}$ ). After that, 1 or $10 \mathrm{ml}$ of the bacterial solution containing $10^{8}$ or $10^{9}$ colony forming units per ml (CFU ml-1) were used to inoculate plants in $1-\mathrm{I}$ or $10-\mathrm{I}$ pots respectively. Bacterial inoculation was performed during sowing, as described below. First, the pots were saturated with tap water, and then, the seeds were sown to a depth of $1 \mathrm{~cm}$. Subsequently, the holes generated by seeding were filled with soil. Finally, the bacterial suspensions were added in the middle of the pots. Nitrogen fertilization positive controls were performed adding $400 \mathrm{mg}$ or $4 \mathrm{~g}$ of $\left(\mathrm{NH}_{4}\right)_{2} \mathrm{SO}_{4}$ in the 1-I and 10-I pots respectively. This fertilization was performed twice: on the sowing day and 20 days later. Plants were grown in a greenhouse and irrigated with non-sterile tap water. The greenhouse temperature ranged between $9^{\circ} \mathrm{C}$ and $18^{\circ} \mathrm{C}$ for wheat and between $16^{\circ} \mathrm{C}$ and $25^{\circ} \mathrm{C}$ for maize, with an average photoperiod of 10 and $14 \mathrm{~h}$ for wheat and maize respectively. 
Supplemental lighting was used at an intensity of $198 \mu \mathrm{mol}$ $\mathrm{m}^{-2} \mathrm{~s}^{-1}$. Maize controlled fecundation was performed by hand pollination. For this, male and female inflorescences were covered with paper bags. Pollen collected from each plant was applied to a silk of a different plant (from the same treatment) every day during the receptive period of the silks (approximately 5 days). To measure dry weight, the aerial part of 2-month-old plants and seeds were dried for $48 \mathrm{~h}$ at $60^{\circ} \mathrm{C}$. Seed number and seed weight were recorded for each plant. Soil mineral nitrogen was measured as previously described (Setten et al., 2013) and total nitrogen content in plant matter was established by the Kjeldahl method. Briefly, $150 \mathrm{mg}$ of plant dry matter (green tissue or seed) were digested and distilled on VELP units following the company's instructions (VELP Scientifica, Italy). Distilled nitrogen (ammonium) was titrated using $0.005 \mathrm{~N} \mathrm{H}_{2} \mathrm{SO}_{4}$. Nitrogen determinations were performed in Laboratorios Fox (www.foxlab.com.ar). Dehydrogenase activity in soil samples was analysed by the reduction of triphenyltetrazolium chloride according to Casida et al. (1964). The nitrogen fixation process in the roots, stems and leaves (15 mg dry weight) was measured in 10-ml tubes filled with well water sterilized by filtration. Homogenized soil samples without roots were transferred to the pre-weighed containers by using a plastic syringe with the luer tip removed. Then, $2 \mathrm{ml}$ of these soil samples were transferred to 10-ml tubes. The upper space of the containers was exchanged by gaseous nitrogen. Nitrogenase activity was evaluated by acetylene reduction as previously described (Setten et al., 2013). For root-adhesion assays, the cosmid X940 was introduced by transformation into competent cells of the Pf-5-derived lapA mutant (Pf-5 lapA::KmR) and its complemented derived strain (Pf-5 lapA:Km+lapA) (Ayub et al., 2015). Transformants were selected by plating on $\mathrm{L}$ agar medium without $(\mathrm{NH} 4)_{2} \mathrm{SO}_{4}$ according to Setten et al. (2013). The recombinant strains containing the cosmid $\mathrm{X} 940$ were named Pf-5 X940lapA::KmR and Pf-5 X940-lapA::KmR+lapA. BNF was evaluated in the lapA mutants by acetylene reduction assays in Erlenmeyer flasks with plastic screw caps under nitrogenlimiting conditions according to Setten et al. (2013).

\section{Bacterial localization assays on maize and wheat-soil system}

Greenhouse maize and wheat plants were inoculated with Pseudomonas strains as described above, but using the GFPtagged strains Pf-5-ChrGFP and Pf5 X940-ChrGFP. Bacterial persistence and colonization of maize and wheat roots and soil were studied for 2 months after inoculation. First, the aerial green tissues were cut $1 \mathrm{~cm}$ above the soil, washed with tap water and placed in 50-ml tubes containing $25 \mathrm{ml}$ of saline solution $\left(0.9 \% \mathrm{w} \mathrm{v}^{-1} \mathrm{NaCl}\right)$. Then, the roots were carefully washed with tap water to remove adhering soil particles, and placed in $50-\mathrm{ml}$ tubes containing $25 \mathrm{ml}$ of saline solution. The tubes were vortexed for $2 \mathrm{~min}$ and centrifuged at $4000 \times g$ and $4^{\circ} \mathrm{C}$ for $15 \mathrm{~min}$. The supernatants were removed, leaving $1 \mathrm{ml}$ of saline solution in each tube. For surface colony counts, named phyllosphere or rhizosphere depending on their tissue origin, aliquots were plated in selective minimal medium NL (7.5 mM KH $\mathrm{PO}_{4}, 17.22 \mathrm{mM} \mathrm{K} \mathrm{HPO}_{4}, 3.42 \mathrm{mM} \mathrm{NaCl}$,
$7.57 \mathrm{mM}\left(\mathrm{NH}_{4}\right)_{2} \mathrm{SO}_{4}, 2 \mathrm{mM} \mathrm{MgSO}{ }_{4} 7 \mathrm{H}_{2} \mathrm{O}, 3.7 \mu \mathrm{M} \mathrm{FeCl}$ $6 \mathrm{H}_{2} \mathrm{O}, 0.1 \mu \mathrm{M} \mathrm{CuCl}_{2} 2 \mathrm{H}_{2} \mathrm{O}, 0.1 \mu \mathrm{M} \mathrm{ZnSO}_{4} 7 \mathrm{H}_{2} \mathrm{O}, 0.73 \mu \mathrm{M}$ $\mathrm{MnCl}_{2} \mathrm{H}_{2} \mathrm{O}, 1 \mu \mathrm{M} \mathrm{CaCl}_{2} 2 \mathrm{H}_{2} \mathrm{O}, 0.21 \mu \mathrm{M} \mathrm{NaMoO}_{4}, 3.4 \mathrm{mM}$ citric acid, $0.25 \% \quad \mathrm{w} \mathrm{v} \mathrm{v}^{-1}$ octanoate and $30 \mu \mathrm{g} \mathrm{ml}^{-1}$ chloramphenicol, $\mathrm{pH}=7$ ) and incubated for two days at $28^{\circ} \mathrm{C}$ to determine the number of CFU. For surface-sterilization of plant tissues, the tubes were vortexed with a solution $1 \%$ $\mathrm{v} \mathrm{v}^{-1}$ sodium hypochlorite, $0.1 \% \mathrm{w} \mathrm{v}^{-1}$ SDS, $0.2 \% \mathrm{v} \mathrm{v}^{-1}$ Tween-20 for $2 \mathrm{~min}$. The solution was discarded and tissues were washed with sterilized distilled water. Then, a solution $70 \% \mathrm{v} \mathrm{v}^{-1}$ ethanol was added to the tubes and incubated for $3 \mathrm{~min}$. After that, the tissues were washed four times with sterilized distilled water. The tissues were then vortexed in the last wash for $1 \mathrm{~min}$. The tubes were centrifuged at $4000 \times g$ and $4^{\circ} \mathrm{C}$ for $15 \mathrm{~min}$. The supernatants were removed, leaving $1 \mathrm{ml}$ of saline solution. Then, $100 \mu \mathrm{l}$ was plated in LN medium to determine the number of CFU, as described above, as disinfection control. Experiments showing bacteria in this control were discarded. Tissues were macerated using a mortar on saline solution (1 or $2 \mathrm{ml}$ depending on the amount of tissue) and aliquots were prepared to determine the CFU of endophytes using LN medium as described previously. To analyse the persistence of bacteria outside the host plant, the soil from each pot was vigorously mixed and two 8-g samples were taken: one to analyse the amount of Pf-5-ChrGFP and Pf5 X940ChrGFP strains and the other to determine soil dry weight. To determine the amount of GFP-tagged bacteria, the soil was mixed with $40 \mathrm{ml}$ of saline solution, vortexed for 2 min and aliquots taken to determine the CFU of bacteria present in the soil as described above. In all the cases, Pf-5ChrGFP and Pf5 X940-ChrGFP counts were performed analyzing the number of GFP-expressing colonies using a fluorescence magnifying glass. The phyllosphere, rhizosphere and endophytic compartments were operationally defined as schematically shown in Fig. 4B.

\section{Visualization of bacterial root-colonization by CLSM}

Wheat seeds were surface-sterilized using $2 \% \quad v \quad v^{-1}$ sodium hypochlorite for $3 \mathrm{~min}, 70 \% \mathrm{v} \mathrm{v}^{-1}$ ethanol for $3 \mathrm{~min}$ and washing three times with sterilized distilled water. Seeds were incubated on petri dishes with $1 \%$ agar water for $24 \mathrm{~h}$ before inoculation. Pf-5-pMP4655GFP and Pf5 X940-pMP4655GFP were cultured overnight, centrifuged at $4000 \times g$ for $15 \mathrm{~min}$, washed with saline solution $(0.9 \% \mathrm{w}$ $\mathrm{v}^{-1} \mathrm{NaCl}$ ) and diluted to an $\mathrm{OD}_{600} 0.15$. Seeds were incubated with the bacterial suspension for $10 \mathrm{~min}$ and placed on filter papers for $2 \mathrm{~min}$ to remove the excess bacterial suspension. Then, seeds were transferred to sterile cottonstoppered glass tubes with $0.4 \% \mathrm{w} \mathrm{v}^{-1}$ agar-water medium. Plants were grown for 21 days in a growth chamber, with a $16 \mathrm{~h}$ light/ $8 \mathrm{~h}$ dark cycle and a constant temperature of $25^{\circ} \mathrm{C}$. After 21 days, roots were washed with saline solution, cut in small pieces (around $1 \mathrm{~cm}$ ) within $2-8 \mathrm{~cm}$ of the root tip. The root sections were observed by scanning different focal planes of the surface using a C-Apochromat $40 \mathrm{X} / 1.2$ objective from a laser scanning confocal microscope (LSM 510 Pascal, Microlmaging, Oberkochen, Germany), using a $488 \mathrm{~nm}$ argon laser excitation and 
$500 \mathrm{~nm}$ long pass emission filter. Representative projections of CSLM images are shown.

\section{${ }^{15} \mathrm{~N}$ isotope dilution analysis}

An isotope dilution strategy (McAulie et al., 1958), consisting in treating the $1-1$ pots containing the maize and wheat-soil system with $36 \mathrm{mg}$ of $\mathrm{NH}_{4}\left(\mathrm{SO}_{4}\right)$ with 10 atom $\%{ }^{15} \mathrm{~N}$ excess on the sowing day, was used to measure the incorporation of nitrogen derived from BNF into maize and wheat under greenhouse conditions as described above with slight modifications. Pf-5- and Pf5 X940-treated plants growing in ${ }^{15} \mathrm{~N}$-supplemented soil for one or 2 months were harvested to evaluate the quantity of nitrogen obtained by BNF. Whole plants were washed with distilled water and then different tissues were separated and dried at $67^{\circ} \mathrm{C}$ for 4 days. The tissues were weighed and finely ground and $6-\mu \mathrm{g}$ samples were taken to analyse the nitrogen content by using continuous-flow mass spectrometer ANCA-SL (Europa Scientific). Stable isotope ratios were reported as $\delta{ }^{15} \mathrm{~N}$, a value given in parts per thousand $(\%)$. The nitrogen derived from gaseous nitrogen (\%Ndfa) in wheat plants inoculated with Pf-5 X940 was measured using the following calculation: \%Ndfa $=100\left[1-\left(\delta^{15} \mathrm{~N}\right.\right.$ Pf-5 X940-treated plants/Pf-5-treated plants)].

\section{Acknowledgements}

We thank Carmen Soria and Guillermo Piparola for their technical support. We are grateful to Dr. Guido Bloemberg for the gift of plasmid pMP4655. This work was supported by grants PICT-2011-1325, PICT-2014-1397 and PICT-2014-3659 to N.D.A.

\section{References}

Ayub, N.D., Julia Pettinari, M., Mendez, B.S., and Lopez, N.I. (2006) Impaired polyhydroxybutyrate biosynthesis from glucose in Pseudomonas sp. 14-3 is due to a defective betaketothiolase gene. FEMS Microbiol Lett 264: 125-131.

Ayub, N.D., Fox, A.R., Garcia, A.N., Mozzicafreddo, M., Cuccioloni, M., Angeletti, M., et al. (2015) Pseudomonas fluorescens Pf-5 genome-wide mutant screen for resistance to the antimicrobial peptide alfalfa snakin-1. FEMS Microbiol Lett 362: 1-6.

Bao, Y., Lies, D.P., Fu, H., and Roberts, G.P. (1991) An improved Tn7-based system for the single-copy insertion of cloned genes into chromosomes of gram-negative bacteria. Gene 109: 167-168.

Barahona, E., Navazo, A., Yousef-Coronado, F., Aguirre de Carcer, D., Martinez-Granero, F., Espinosa-Urgel, M., et al. (2010) Efficient rhizosphere colonization by Pseudomonas fluorescens $\mathrm{f} 113$ mutants unable to form biofilms on abiotic surfaces. Environ Microbiol 12: 3185-3195.

Bloemberg, G.V., Wijfjes, A.H., Lamers, G.E., Stuurman, N., and Lugtenberg, B.J. (2000) Simultaneous imaging of Pseudomonas fluorescens WCS365 populations expressing three different autofluorescent proteins in the rhizosphere: new perspectives for studying microbial communities. Mol Plant Microbe Interact 13: 1170-1176.

Casida, L., Klein, D., and Santoro, T. (1964) Soil Dehydrogenase Activity. Soil Science 98: 371-376.
Chin-A-Woeng, T.F.C., de Priester, W., van der Bij, A.J., and Lugtenberg, B.J.J. (1997) Description of the colonization of a gnotobiotic tomato rhizosphere by pseudomonas fluorescens biocontrol strain WCS365, using scanning electron microscopy. Mol Plant Microbe Interact 10: 79-86.

de Morais, R.F., Quesada, D.M., Reis, V.M., Urquiaga, S., Alves, B.J.R., and Boddey, R.M. (2011) Contribution of biological nitrogen fixation to Elephant grass (Pennisetum purpureum Schum.). Plant and Soil 356: 23-34.

Dixon, R.A., and Postgate, J.R. (1971) Transfer of nitrogenfixation genes by conjugation in Klebsiella pneumoniae. Nature 234: 47-48.

Dos Santos, P.C., Fang, Z., Mason, S.W., Setubal, J.C., and Dixon, R. (2012) Distribution of nitrogen fixation and nitrogenase-like sequences amongst microbial genomes. BMC Genomics 13: 162.

Duque, E., de la Torre, J., Bernal, P., Molina-Henares, M.A., Alaminos, M., Espinosa-Urgel, M., et al. (2013) Identification of reciprocal adhesion genes in pathogenic and nonpathogenic Pseudomonas. Environ Microbiol 15: 36-48.

Erisman, J.W., Bleeker, A., Galloway, J., and Sutton, M.S. (2007) Reduced nitrogen in ecology and the environment. Environ Pollut 150: 140-149.

Farrar, K., Bryant, D., and Cope-Selby, N. (2014) Understanding and engineering beneficial plant-microbe interactions: plant growth promotion in energy crops. Plant Biotechnol $J$ 12: 1193-1206.

Figuerola, E.L., Guerrero, L.D., Rosa, S.M., Simonetti, L., Duval, M.E., Galantini, J.A., et al. (2012) Bacterial indicator of agricultural management for soil under no-till crop production. PLoS One 7: e51075.

Finan, T.M., Kunkel, B., De Vos, G.F., and Signer, E.R. (1986) Second symbiotic megaplasmid in Rhizobium meliloti carrying exopolysaccharide and thiamine synthesis genes. J Bacteriol 167: 66-72.

Galloway, J.N., Townsend, A.R., Erisman, J.W., Bekunda, M., Cai, Z., Freney, J.R., et al. (2008) Transformation of the nitrogen cycle: recent trends, questions, and potential solutions. Science 320: 889-892.

Geddes, B.A., Ryu, M.H., Mus, F., Garcia Costas, A., Peters, J.W., Voigt, C.A., and Poole, P. (2015) Use of plant colonizing bacteria as chassis for transfer of $\mathrm{N}$-fixation to cereals. Curr Opin Biotechnol 32: 216-222.

Hinsa, S.M., Espinosa-Urgel, M., Ramos, J.L., and O'Toole, G.A. (2003) Transition from reversible to irreversible attachment during biofilm formation by Pseudomonas fluorescens WCS365 requires an $\mathrm{ABC}$ transporter and a large secreted protein. Mol Microbiol 49: 905-918.

Howell, C.R., and Stipanovic, R.D. (1979) Control of Rhizoctonia solani on cotton seedlings with Pseudomonas fluorescens with an antibiotic produced by the bacterium. Phytopathology 69: 480-482.

Knoth, J.L., Kim, S.H., Ettl, G.J., and Doty, S.L. (2014) Biological nitrogen fixation and biomass accumulation within poplar clones as a result of inoculations with diazotrophic endophyte consortia. New Phytol 201: 599-609.

Koch, B., Jensen, L.E., and Nybroe, O. (2001) A panel of Tn7-based vectors for insertion of the gfp marker gene or for delivery of cloned DNA into Gram-negative bacteria at a neutral chromosomal site. J Microbiol Methods 45: 187195. 
Lambertsen, L., Sternberg, C., and Molin, S. (2004) Mini-Tn7 transposons for site-specific tagging of bacteria with fluorescent proteins. Environ Microbiol 6: 726-732.

Loper, J.E., Kobayashi, D.Y., and Paulsen, I.T. (2007) The genomic sequence of Pseudomonas fluorescens Pf-5: insights into biological control. Phytopathology 97: 233-238.

McAulie, C., Chamblee, D.S., Uribe-Arango, H., and Woodhouse, W.W. (1958) Influence of inorganic nitrogen on nitrogen fixation by legumes as revealed by $15 \mathrm{~N}$. Agro J 50: 334-337.

Mercado-Blanco, J., Alos, E., Rey, M.D., and Prieto, P. (2016) Pseudomonas fluorescens PICF7 displays endophytic lifestyle in cultivated cereals and enhances yield in barley. FEMS Microbiol Ecol (in press). doi: 10.1093/femsec/fiw092.

Miller, V.L., and Mekalanos, J.J. (1988) A novel suicide vector and its use in construction of insertion mutations: osmoregulation of outer membrane proteins and virulence determinants in Vibrio cholerae requires toxR. $J$ Bacteriol 170: 2575-2583.

Newell, P.D., Monds, R.D., and O'Toole, G.A. (2009) LapD is a bis-(3',5')-cyclic dimeric GMP-binding protein that regulates surface attachment by Pseudomonas fluorescens Pf0-1. Proc Natl Acad Sci U S A 106: 3461-3466.

Oldroyd, G.E., and Dixon, R. (2014) Biotechnological solutions to the nitrogen problem. Curr Opin Biotechnol 26: 19-24.

Oldroyd, G.E., Murray, J.D., Poole, P.S., and Downie, J.A. (2011) The rules of engagement in the legume-rhizobial symbiosis. Annu Rev Genet 45: 119-144.

Olivares, J., Bedmar, E.J., and Sanjuan, J. (2013) Biological nitrogen fixation in the context of global change. Mol Plant Microbe Interact 26: 486-494.

Pascuan, C., Fox, A.R., Soto, G., and Ayub, N.D. (2015) Exploring the ancestral mechanisms of regulation of horizontally acquired nitrogenases. $J$ Mol Evol 81: 84-89.

Peters, J.W., and Szilagyi, R.K. (2006) Exploring new frontiers of nitrogenase structure and mechanism. Curr Opin Chem Biol 10: 101-108.

Prieto, P., and Mercado-Blanco, J. (2008) Endophytic colonization of olive roots by the biocontrol strain Pseudomonas fluorescens PICF7. FEMS Microbiol Ecol 64: 297-306.

Santi, C., Bogusz, D., and Franche, C. (2013) Biological nitrogen fixation in non-legume plants. Ann Bot 111: 743-767.

Setten, L., Soto, G., Mozzicafreddo, M., Fox, A.R., Lisi, C., Cuccioloni, M., et al. (2013) Engineering Pseudomonas protegens Pf-5 for nitrogen fixation and its application to improve plant growth under nitrogen-deficient conditions. PLoS One 8: e63666.

Stueken, E.E., Buick, R., Guy, B.M., and Koehler, M.C. (2015) Isotopic evidence for biological nitrogen fixation by molybdenum-nitrogenase from 3.2 Gyr. Nature 520: 666669.

Temme, K., Zhao, D., and Voigt, C.A. (2012) Refactoring the nitrogen fixation gene cluster from Klebsiella oxytoca. Proc Natl Acad Sci U S A 109: 7085-7090.

USDA (2014) United States Department of Agriculture National Agricultural Statistics Service (USDA-NASS).
2014. Table 7. Average U.S. farm prices of selected fertilizers. Washington, DC. http://www.ers.usda.gov/data-products/fertilizer-use-and-price.aspx\#26727.

Venkateshwaran, M. (2015) Exploring the feasibility of transferring nitrogen fixation to cereal. Crops 403-410.

Wang, L., Zhang, L., Liu, Z., Zhao, D., Liu, X., Zhang, B., et al. (2013a) A minimal nitrogen fixation gene cluster from Paenibacillus sp. WLY78 enables expression of active nitrogenase in Escherichia coli. PLoS Genet 9: e1003865.

Wang, X., Yang, J.G., Chen, L., Wang, J.L., Cheng, Q., Dixon, R., and Wang, Y.P. (2013b) Using synthetic biology to distinguish and overcome regulatory and functional barriers related to nitrogen fixation. PLoS One 8: e68677.

Welsh, D.T. (2000) Nitrogen fixation in seagrass meadows: regulation, plant-bacteria interactions and significance to primary productivity. Ecol Lett 3: 58-71.

Witcombe, J.R., Hollington, P.A., Howarth, C.J., Reader, S., and Steele, K.A. (2008) Breeding for abiotic stresses for sustainable agriculture. Philos Trans $R$ Soc Lond B Biol Sci 363: 703-716.

Yang, J., Xie, X., Wang, X., Dixon, R., and Wang, Y.P. (2014) Reconstruction and minimal gene requirements for the alternative iron-only nitrogenase in Escherichia coli. Proc Natl Acad Sci U S A 111: E3718-3725.

Zakry, F.A.A., Shamsuddin, Z.H., Abdul Rahim, K., Zawawi Zakaria, Z., and Abdul Rahim, A. (2012) Inoculation of Bacillus sphaericus UPMB-10 to young oil palm and measurement of its uptake of fixed nitrogen using the $15 \mathrm{~N}$ isotope dilution technique. Microbe Environ 27: 257-262.

\section{Supporting information}

Additional Supporting Information may be found in the online version of this article at the publisher's web-site:

Fig. S1. Effects of the inoculation with Pf-5 X940 on the levels of inorganic nitrogen in soil. Two months after inoculation, nitrate and ammonium compounds were measured in the soils. The statistical analysis was carried out with ANOVA followed by Dunnett's contrast test $\left({ }^{* *} P<0.001\right.$, ${ }^{\star} P<0.05$, n.s. not significant). All values are means + SEM $(n=16)$.

Fig. S2. Effects of the inoculation with Pf-5 X940 on the levels of microbial activity in soil. Two months after inoculation, dehydrogenase activities were measured in the soils. The statistical analysis was carried out with ANOVA followed by Dunnett's contrast test $\left({ }^{\star * *} P<0.0001\right.$, n.s. not significant). All values are means $+\operatorname{SEM}(n=16)$.

Fig. S3. Visualization under confocal laser scanning microscopy of colonization by the fluorescent-tagged bacterium Pf5-pMP4655GFP on the surface of wheat roots. Picture A, $C$ and D show CLSM images of Pf-5 GFP-tagged cells during root surface colonization, and picture $B$ shows orthogonal planes of the confocal image presented in picture $A$. 